\title{
Erratum to: Dose-Specific Adverse Drug Reaction Identification in Electronic Patient Records: Temporal Data Mining in an Inpatient Psychiatric Population
}

\author{
Robert Eriksson - Thomas Werge • \\ Lars Juhl Jensen · Søren Brunak
}

Published online: 9 April 2014

(C) Springer International Publishing Switzerland 2014

Erratum to: Drug Saf (2014) 37:237-247

DOI 10.1007/s40264-014-0145-z

Page 237, abstract, paragraph 4, lines 13-14: The following sentence, which previously read:

"five patients exhibited a significant difference $(p<0.05)$ " should read:

"five antipsychotics exhibited a significant difference $(p<0.05)$ ".

The online version of the original article can be found under doi:10.1007/s40264-014-0145-z.

R. Eriksson · L. J. Jensen · S. Brunak ( $₫)$

NNF Center for Protein Research, Department of Disease

Systems Biology, Faculty of Health and Medical Sciences,

University of Copenhagen, Blegdamsvej 3B,

2200 Copenhagen, Denmark

e-mail: soren.brunak@cpr.ku.dk

R. Eriksson $\cdot$ S. Brunak

Center for Biological Sequence Analysis,

Department of Systems Biology,

Technical University of Denmark, Lyngby, Denmark

T. Werge

The Research Institute of Biological Psychiatry,

Mental Health Centre Sct. Hans,

Copenhagen University Hospital, Roskilde, Denmark 